\title{
An Investigation into the Role of Tablet Devices in Facilitating Collaborative Learning in EFL Language Course
}

\author{
https://doi.org/10.3991/ijet.v12i04.6732 \\ Haifa Albadry \\ Newcastle University, Newcastle upon Tyne, UK \\ h.f.albadry@ncl.ac.uk
}

\begin{abstract}
The following paper outlines research concerning the ways in which learners use tablet devices, namely the iPad device, to learn English both in and outside of the classroom and how students' interdependence and collaborative learning may be fostered by such an approach.

The study comprised of 21 Saudi university students at Dammam University, who were provided with the iPad device over a 12-week period. The potential use of the device as a mediating learning tool, in order to develop students' collaboration and interaction, is discussed with reference to data compiled from students' learning diaries, focus group interviews, and online log files.

The results suggest tablet devices aid learning by providing meaningful opportunities to use the target language in context and encouraging collaborative interaction. The findings also indicate that various types of teacher support, as well as interaction with the teacher and other students, remain necessary alongside tablet-assisted language learning.
\end{abstract}

Keywords-Mobile Assisted Language Learning, Language Learning, Collaboration, Interdependence, Tablet device

\section{Introduction}

Recent fundamental changes in the approach to teaching and learning in higher education institutions within the Saudi Arabian education system can be attributed to a number of interconnected factors. Firstly, the rise of information and communication technology has unequivocally advanced the support available during distance or 'elearning' projects. Heavy investment in technology has also enhanced the learning experience through the use of virtual learning environments, blackboards, Moodle, and self-access learning suites. Furthermore, such developments are aided by the ever-increasing spread of the Internet and mobile devices, such as mobile phones, PDAs (personal digital assistants) and tablet devices.

At the same time, several reasons exist which have limited the learning outcome in many of these institutions. These include: 
- Year by year increases in the number of university student enrolments

- Large class size and time constraints

- The persistence of a teacher-centred approach, contributing to: a lack of studentstudent and teacher-student interaction, narrow exposure to the target language, limited opportunities for authentic target language use

- Inadequate support for learners, which hinders effective use of the available facilities

- A lack of authentic teaching and learning materials

- Exam-orientated pedagogy

- Social barriers within Saudi Arabian society which result in the cultural inhibition of informal social communication for language learning outside of the classroom. This therefore critically hinders social use of the target language.

The above issues present a clear need for the re-examination of the education system and its current pedagogical practice. This study aims to address a number of those through not least increasing the exposure of language learners to learning opportunities, reducing time and space constraints, and providing access to a wealth of authentic materials. Incorporating technology, such as the iPad device, to meet such needs of the teacher and learner is a proposal that must first be carefully examined. Specifically, its ability and potential to deliver a tailored learning experience to a diverse range of learners will be investigated.

\section{Literature Review}

Sustained interaction among learners is seen to be a key factor in building knowledge and developing collective cognitive responsibility [17]. In fact, it is thought that learning cannot be achieved individually and is rather a process of communication and interaction with other learning groups, such as multiple peers, classmates and instructors. Alongside this, collaboration is noted by Jones, et al. [8, p. 254] to be motivational due to its 'distinct, important emotional dimension'. Crook [4] further describes that motivation is brought about by the shared experience learners undergo in negotiating 'shared meaning' as part of their unique learning process.

Becta [1] identified the potential for mobile technology to provide the conditions for collaborative learning, communication, and independent learning among students. This can be attributed to a number of properties. Firstly, mobile technology allows learners to collect and share data in real-time, and transmits and delivers rich multimedia content [9] and [13]. The provision of feedback from the teacher and other learners without disruption of the learning process is also made possible [3]. Indeed, through the different communication channels offered by mobile technology, such as e-mails, messages, blogs, meeting platforms, and forums, the practical relationship between learners, their peers and their teacher is seen to be improved [5]. Mobile learning caters for a range of contexts, creating the opportunity to interact with learners wherever their location. Ryu and Parsons [15, p.11] also emphasise that collaborative learning is enhanced by 'strengthening the organisation of the learning material 
and information, supporting communication among group members, and helping the coordination between the learning activities'.

Mobile Assisted Language Learning (MALL) exists as a sub-area of the so-called M-Learning (mobile learning) and Computer Assisted Language Learning (CALL) and is fast gaining popularity in this field of language learning research. It is considered emerging approach to language learning that enables access to authentic language learning content and increased communicative practice [18]. Enhanced by the combined introduction of handheld mobile devices and wireless networking, it is said to be 'a stepping stone toward more authentic communication' [11, p.7]. Both the portability and connectivity of mobile technology are especially key properties for those learners constrained by time, access to materials and practice, or boundaries between the classroom and the external world. In contrast to CALL, MALL learners are not restricted in their access to materials nor limited to the classroom or a fixed place of learning. Learning is therefore more personalised, situated, and authentic [10]. This spontaneity and the continuous nature of interaction, enabled by the portable devices used in MALL, are seen to be main differences between these two approaches, and indeed the main advantages of MALL over CALL. As KukulskaHulme et al [12, p.7] state, through MALL teachers are able to facilitate learning practices which encompass 'good language teaching philosophy'. Examples of these are not limited to but include the opportunity to: create and share multi-modal texts, interact spontaneously with a range of people, capture language outside of the classroom, monitor their own language production, assess their learning needs, and provide evidence of language gathered, across a range of contexts and media forms.

\section{Theoretical Foundation: Socio-cultural Theory}

Sociocultural theory can be said to reflect a constructivist viewpoint in which social context is placed central to the success of learning. Indeed, such thinking defines learning as the reconstruction of knowledge and asserts that this requires collaborative interaction, social communication, and the sharing of meaning either directly or through mediated tools [14]. It is this notion of learning as above all a social process which guides this project forward.

As MALL promotes connectivity and interaction between learners (at any time and at any location) the learners' ability to communicate and share knowledge outside of the classroom is improved. The expansion of opportunities for social learning provided for by MALL enables learners to challenge pre-conceived ideas and helps to expand their cognitive schemata.

The concept of tool mediation as described by Vygotsky [19] has also been relevant in the study of MALL. This concept views the learning process as self-regulating and not controlled by either teacher or syllabus; the teacher and classroom environment serve merely as mediators for the second language learning process. The traditional classroom dynamic where teachers possess control over discussions is viewed as a hindrance preventing learners from taking responsibility and initiative for their learning. In order to overcome this, the learners must be granted greater participation 
rights and opportunities to engage in social aspects, while the teacher should relinquish some of their power.

It is clear new possibilities are afforded by tablet technology. The iPad in this study allowed students to overcome the traditional restrictions of time and location associated with traditional classroom based learning. It therefore offered new social methods of learning particularly helpful to those with limited opportunities for target language exposure. Yet, it was observing the impact such possibilities have on the second language learning process that was the key objective of this study.

\section{$4 \quad$ Study Design}

\subsection{Aims of the Study}

This study sought to investigate the extent to which the introduction of tablet devices to learners on a language course could encourage collaborative learning, and help to overcome issues such as time and space restrictions, lack of learning materials and an exam-orientated education system. It looked at how learners used tablet devices as part of their daily language learning practice as well as the ways in which the introduction of these devices into university classrooms altered the traditional student/teacher dynamic.

\subsection{Case Study}

The case in this study is the experience of a group of Saudi participants of a syllabus in an EFL (English for Foreign Language) course on the iPad under the guidance of their instructor. Case study design was selected as the most appropriate design for the aim of this project because the research is exploratory in nature as it focused on understanding a particular experience of one group of students to gain a greater understanding of the Saudi context in which the study was implemented as well as the reaction of the participants.

\subsection{Participants}

The 21 participants in this study were exclusively female native speakers of Arabic between the ages of 19-24. They were all majoring in computer science at Community College, Dammam University in Saudi Arabia, and were classified as beginner level learners of English. The linguistic competence of the students was assessed based on the scores derived from the results obtained during the first semester exam of their study at the English department prior to conducting this study. The five language skills considered in order to determine the students' language proficiency were: grammar, listening, speaking, reading, and writing. The students' classification into groups was based on the English Department evaluation system. 


\subsection{Data Collection}

There were three sources of data collected from the learners in this study. Weekly diary entries were submitted with the students' agreement, these ranged in length from a mere five lines to a lengthy four pages. In addition, focus group interviews were conducted with all the students in their native language and audiotaped to ensure accurate transcription. The third method of data collection was through online tracker $\log$ files. Two systems were used to collect the log files: the iKey monitor software package, and Meraki device management software. The data obtained from these three sources were compared against each other to ensure reliability.

\subsection{Data Analysis}

For the diary and focus group data, an inductive thematic analysis was conducted based on Braun and Clarke's [2] six-phase approach: familiarisation with the data, generating initial codes, searching for themes, reviewing themes, defining and naming themes, producing the report.

The first step in analysing students' diaries was preparation of the data, achieved by transforming all electronic and handwritten diaries into Microsoft Word before translating the 70 entries into English. As for the focus group interviews, the taped interviews were transcribed in order to prepare for the analysis stage. The second step was coding the data using the qualitative data analysis program Nvivo 10, which helped manipulate the texts and create codes (known in Nvivo as nodes).

The $\log$ files were created by two monitoring systems (iKey monitor software package, and Meraki device management software) running in the background of students' iPad devices. The software automatically records accurate time-stamped events of how students utilise their iPads in formal and informal settings. Such data was useful in verifying students' use of the device for language learning whether inside or outside classroom and in triangulating students' self-reported data gathered through diaries and focus group interviews.

However, the online log files presented a problem due to the sheer volume of the data collected, a total of 4077 screenshots during the study. As the online tracker data was analysed manually to determine the nature of the activity taking place, it was necessary to sample the data from week 1 , week 4 and week 8 , in order to make the analysis manageable.

\subsection{Materials}

A Wi-Fi enabled $16 \mathrm{G}$ iPad (4 $4^{\text {th }}$ generation) pre-loaded with applications. Several factors helped in the decision of purchasing the iPad in particular: it has a large multitouch display screen $(7.7$ inch) which resembles the size of a textbook, lightweight, long battery life (about ten hours), built-in microphone and camera, built-in APP (Applications) Store which enables learners to access a wide range of educational, a page layout which can be altered from portrait to landscape, and virtual on-screen keyboard and a single control button. 
In addition, the iBook (electronic version of Q Skills for Success Listening and Speaking Book provided by Oxford University Press) and the iTunes U course management system application was provided to each student. The iBook was created by OUP from scratch and was designed to replicate the look and feel of a traditional paper book but with add-to features to make it more interactive. The book includes features like virtual sticky notes, instant definitions, highlighting, short clips of audio and videos, the ability to save a page and email it, an in-built voice recorder which enables students to practise listening, and the ability to manipulate the size of the text. The appearance and interface of the book is designed to be user-friendly in order to reduce the learning curves usually associated with new technology. The iTune U course, on the other hand, was used in the study to supplement the course materials, organise students' assignments, and interact with students outside the classroom.

\subsection{Procedure}

The course lasted for 10 weeks and consisted of lessons of 2 consecutive hours every day, as well as 5-10 hours per week of outside class learning. For students to be able to gain the most possible benefit from their tablet devices a weekly 2-hour workshop was also held, which included help with any technical difficulties involved and demonstrations of apps.

The in-class activities on this course were drawn from the OUP textbook and included listening, speaking, grammar and vocabulary learning. The outside-class elements of the course aimed at promoting collaborative learning among learners and to help facilitate better communication among themselves and with their teacher. Four separate applications: Ask3, Fuze box, Voice Thread, and Keynote were utilised in a listening and speaking class which supplemented the course and aimed to aid outsideclass learning. Learning tasks using these applications were undertaken in three phases as part of this course.

Phase One: The first phase utilised the Voice Thread App which offers asynchronous video communication. Short podcasts based on pre-selected topics were recorded by learners and uploaded to Voice thread, these could then be viewed by other learners at their convenience. The learners could then engage in text discussion with each other while being monitored and receiving feedback from the teacher through a teachers' account platform. Learners were also able to keep control over the privacy level of their recordings, deciding whether their fellow learners or only the teacher could view it. This privacy feature was particularly helpful in encouraging shy and reluctant learners to share their work and receive feedback.

Phase Two: The second phase utilised the Ask3 application to create a virtual classroom (See figure 1), in which students were required to post recordings of themselves answering questions related to topics covered in their lessons. Unlike the first phase, these recording could be viewed by all the other class members, and discussion and feedback from the classmates were encouraged. 


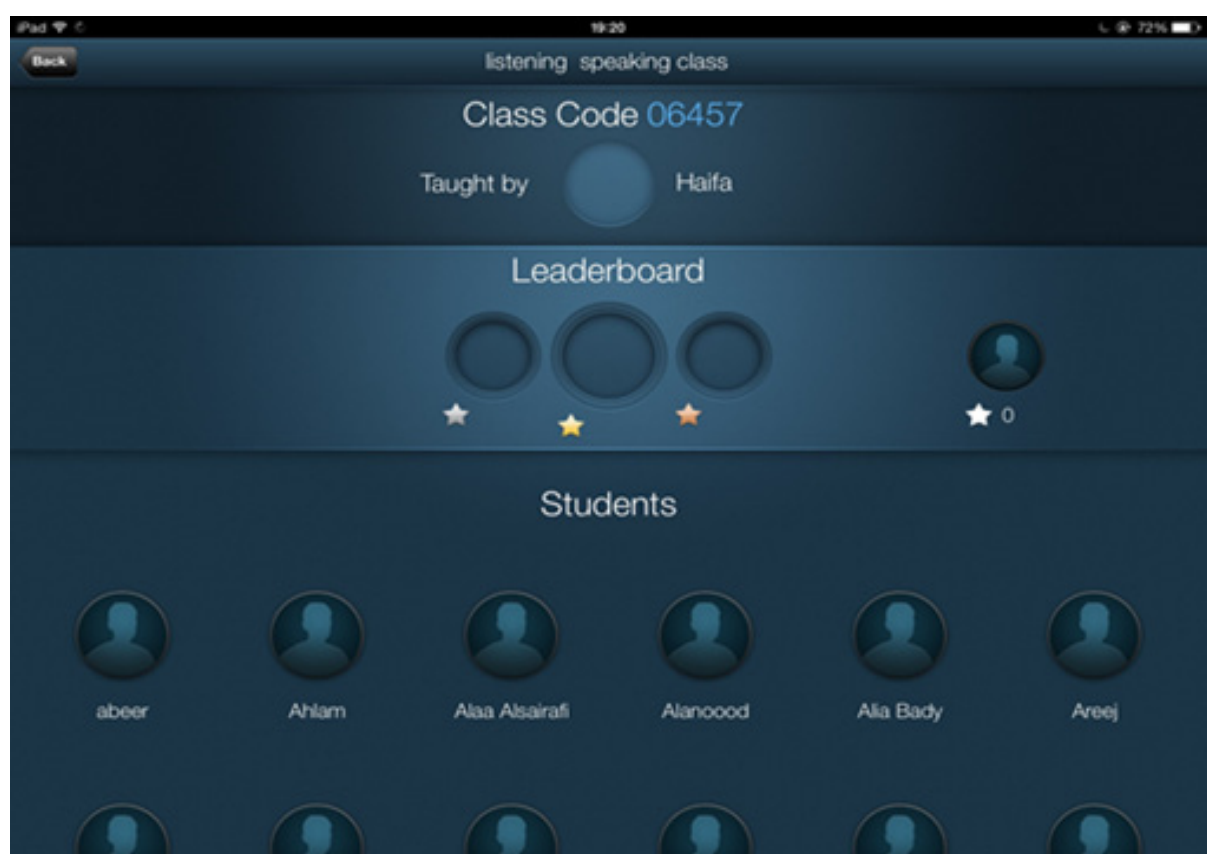

Fig. 1. Screen Capture of Ask3 Virtual Classroom Platform

Phase Three: In the third phase students were divided into groups of 4 and instructed to prepare a 15-minute presentation based on a topic of their choice. This phase utilised the Fuze box application to facilitate discussion and the sharing of ideas amongst learners. They achieved this by setting up online group meetings via Fuze box, where they could receive feedback from their teachers and peers as well as plan and organise their presentation. This phase featured a greater level of confidence and language skill from the learners as they became more familiar with the course.

\section{$5 \quad$ Results and Discussion}

The data collected from the students' diaries and the focus group interviews revealed three distinct forms in which the students experienced collaborative learning. These were: working together, learning from peers and feedback. This section will now look more closely at what the results showed us about each of these forms of collaborative learning.

\subsection{Working Together}

Prior to the course, students were not exposed to group activities as the lecture teaching method was dominant at the college. Hence, teachers played a lead role in classroom interaction for knowledge transmission. Such a teacher-learner relationship and the teaching and learning culture had an impact on students' practice of assistance 
that resulted in a preference for individual learning. For some students, working with others outside the classroom was restricted to their private zone, i.e. their family members. In addition, the limited amount of time during class and school breaks did not afford students the sufficient possibility to work together and exchange knowledge. The introduction of the tablet based activities into students' study did much to help alleviate the time and space restraints which had prevented group learning among students. Due to the introduced access to the tablet devices, the students began to seek out opportunities to take part in group discussions with their fellow learners and perform group activities. This increase in group activity led to students feeling more positive about the learning process.

'for the first time, I have enjoyed learning through group work as it gives me the opportunity to state an opinion'

The increased opportunities for collaboration that the tablet devices afforded led to a willingness in learners to work with peers with whom they would not usually collaborate and so increased students sense of belonging. Being able to collaborate and share feedback and responsibilities with their peers, and work and learn from each other helped students to develop as knowledge generators rather than simply passive learners.

'using the iPad encourages interaction with the students and the teacher using a programme such as the voice recorder means we can listen to the point of view of the students and interact with them'

Initially there were some students who were less willing to contribute and participate in group activities for reasons such as fear or embarrassment of making mistakes or simply because they had become used to their role as passive learners. The evidence shows that the course aided these passive learners to become more active and involved as the course progressed.

Ghadeer: To be honest... at the beginning... it was not suitable for me...I used to

prefer being alone, and even after creating groups I still did not understand anything... but my group taught me and made me love it.

Teacher: You came to love the groups?

Ghadeer: Yes, they gained experience from me and I from them...this means it helps you and makes you love to enter the groups. If I did not know something...I used to ask my group members whether Huda or Nema, and they used to answer me directly... and the same went with them if they did not know anything they would ask me, so there was real teamwork...I used to receive from them and at the same time they used to receive from me and help me... it was a teamwork where everyone assisted each other, and this thing really helped you learn.

The importance that group processes in the classroom have for learners' progress has been outlined in the literature of Dornyei and Murphy [6] and Schmuck and Schmuck [16]. The fact that a social learning environment encouraged learners to contribute and engage in group discussions and activities was also noted by Fleming and Hiple [7]. Such findings are further emphasised by the results of this study. 


\subsection{Learning from Peers}

During the course students were encouraged to use relevant apps on their tablet devices to post their answers to the given tasks, and reflect on the answers of others. The study found that learners on the course used this ability to view their peers work as a source on which to build their own. In this situation, the students' role is transformed from passive learner to active participant with the more knowledgeable learners effectively becoming the expert in the learning process, aiding their less capable peers.

This change to students taking a more active, participatory role in the learning process could be attributed to the new tablet-based learning approach integrated within the course. A key benefit of this approach was the ability for students to access peer support anytime, anywhere. For example, the less capable students made multiple short visits to the different tablet-based communication channels available to them (Ask 3, Voice Thread, Nearpod, etc.), allowing them the additional time necessary to digest and comprehend the various language tasks set for them. The range of different answers given to the tasks helped expose the students to a more varied range of ideas and aided them in developing their understanding.

The sociocultural theory (SCT) perspective on scaffold assistance is therefore supported by the findings of this study. As the Zone of Proximal Development (ZPD) model holds, learners must be provided with appropriate assistance (scaffolding) in order to expand their mental development. With the aid of this scaffolding, learners can perform tasks which previously would have required the assistance of an expert, until eventually the learners may reach a level where they become capable of independent performance and the scaffolding can be withdrawn [19]. This study also identified key mechanisms, such as modelling, cognitive structuring, questioning and feedback, as strategies which more knowledgeable students employed to bridge their less knowledgeable peers' performance in the ZPD.

\subsection{Feedback}

While at first feedback was exclusively between teacher and student (see Figure 2), as the course progressed students were encouraged to give comments and feedback on their peers' contribution.

Peer feedback was particularly evident on the Ask 3 discussion. This primarily consisted of social commentary, including positive remarks, encouraging comments, and compliments. Teacher to student feedback, however, was shaped by the motivation to support the students' performance and consisted of commentary relating to participation level, language form, and knowledge evaluation alongside purposeful encouragement and positive reinforcement.

'It was a good experience to interact with the teacher and receive encouragement and positive reinforcement and pointing out our mistakes and how to correct them through interaction.'

With time, student feedback was positively influenced by that from the teacher. Findings confirmed that students were more likely to elaborate on their comments, providing their own feedback related to the content, form, and linguistic accuracy of 
their peers' contributions as well as commending improvements to performance. In fact, teacher feedback to one individual set about a chain of peer feedback. This ratification of key elements of their responses in turn facilitated the development of shared knowledge.

Central to this development was the visibility of students work and the feedback they received to all online community members. This was enabled by the iPad and the use of different applications. Instant feedback, both written and oral, became a novel part of the interactive process of learning. This allowed learners to share and negotiate and led to increased conversation.

In addition to these factors, a growing familiarity with both their classmates and the course facilitated students' increasing willingness to communicate with their peers and exchange feedback. As students got to know each other better they naturally felt more comfortable sharing their thoughts and feelings with each other.

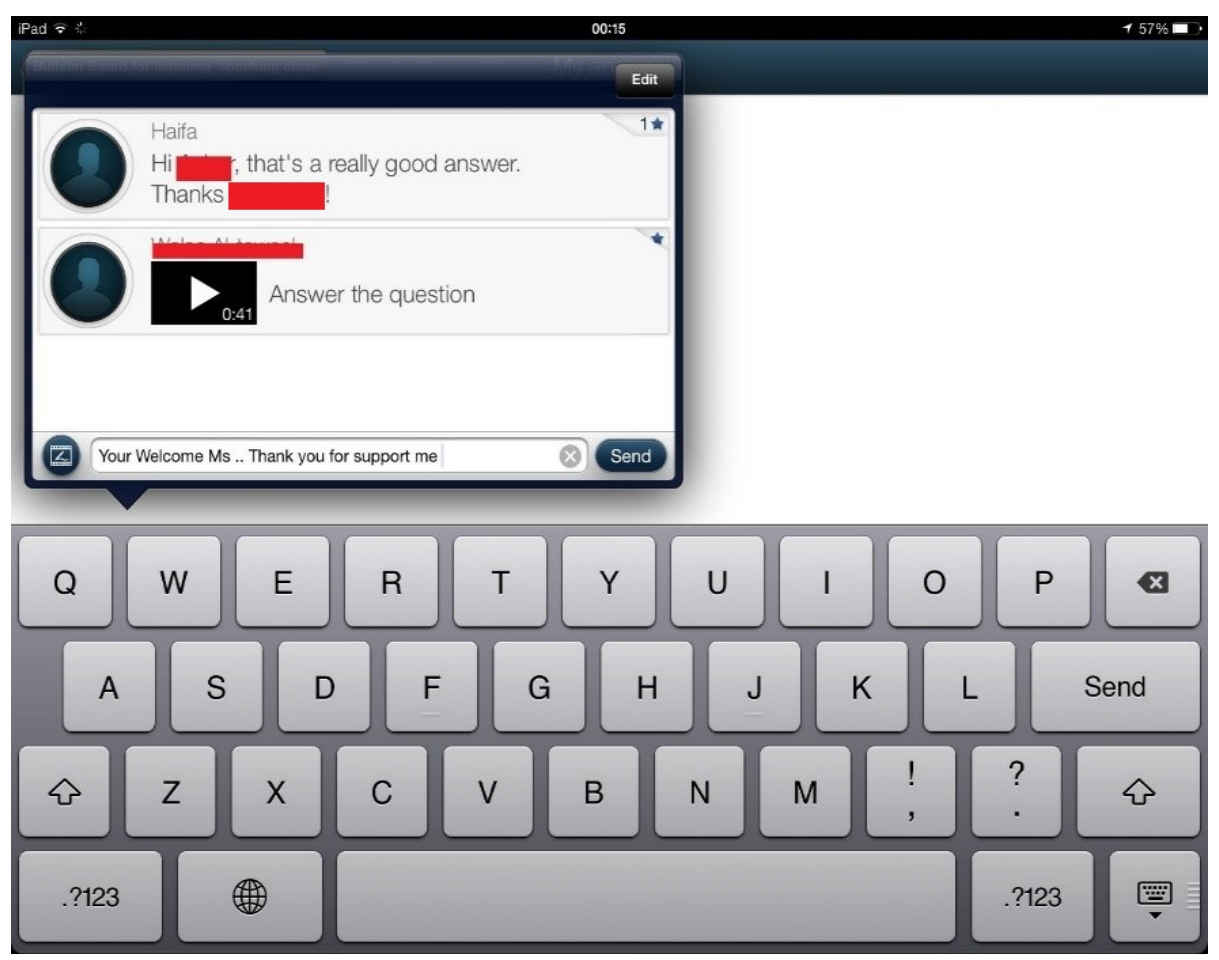

Fig. 2. An Instance of Teacher's Feedback Captured by ikey Monitor

\subsection{Influential factors contributing to students' collaborative learning practices}

Overall, evidence from the data analysis indicated a lack of collaboration by students before the course. This is likely due to several reasons, including traditional teaching methods, time and location constraints, and sociocultural barriers in the Sau- 
di context. As the course progressed, gradual development of collaborative practices was evidenced by the results of the study. Such a change can be attributed to three main factors relating to the affordances provided by the tabled device for collaborative learning: the quantity of communication, the quality of communication, and the control of communication.

The iPad proved to be the ideal tool for maximising communication both between peers and with the teacher due to features such as its light weight, compact size, and ease of use. The student responses in the qualitative date show that these features gave them the ability to access a range of educational application and communication channels. For example, the different communication channels, such as e-mails, messages, meeting platforms, and forums offered by tablet devices increased communication between learners and teachers as well as among learners themselves.

Particularly useful in the Saudi context of this study was the ability the iPad afforded to communicate with other learners anytime, anywhere. This helped students to overcome some of the many social barriers to communication in Saudi culture, supporting Kukulska-Hulme's [10] view that the MALL approach to learning facilitates learner autonomy by making worldwide spontaneous communication possible. This feature also helped to change the students' perception of time allocation and to view learning not as something which only took place during class hours.

A further benefit of the iPad device is the use of the device in public spaces. Some students suggested that using the device in public areas is more appropriate due to its common use among people and particularly the younger generation. According to this view, the iPad is different from was other devices, such as laptops, by being more personal. Unlike the laptop, which is more conspicuous and can draw attention, the iPad for many students provided some privacy as it resembled their other personal devices such as a smart phone. Thus, even in a situation where students were out of their private zone, they were able to use the device for communication with ease and without being embarrassed or self-consciousness. This advantage provided students with a seamless learning experience and maximised their collaborative opportunities within their learning community.

Collaborative opportunities were also maximised within their learning community through the permission of continued conversation despite physical location; peer to peer interaction and interaction with their teachers was no longer confined by traditional practicalities. The anywhere, anytime aspect of these tools altered the quality of teacher-learner and learner-learner communication.

Moreover, using the tablet device and the different collaborative applications changed students' perspective on classroom communication. Interaction with the teacher or their peers was no more related to physical space. Students' collaborative learning became situated in everyday settings and continued despite the constraint of time and space. For example, even when students were absent from school or out of the city, they were able to access their group discussion via the saved feature on the app used. Thus, the tablet devices changed the nature of communication by providing continuity in online face-to-face meetings by providing an archive for absent students. This made it possible for all students to give peer feedback, and to take each other's opinions into account when preparing for a language task. 
Using tablet devices to collaborate increased students' control over location, time, method, and information exchange. The characteristics of the iPad device provided students with instant access to different communication tools, thereby, they were able to choose when and where to communicate. In addition, students were able to select the mode of communication that suited their situation and convenience. Whether using synchronous or asynchronous communication tools, each student had the freedom to select the method of communication based on the level of closeness to her peers or the teacher. For example, in the first weeks of the course, it was found that most students tended to rely on asynchronous communication tools such as email to communicate with the teacher and their peers. As the course progressed, gradually student got to know each other more and adapted themselves to the course. Consequently, they started to contribute more in on-time communication modes, such as online meeting or by sending oral messages. This change can be attributed to the affordance provided by the tablet device for students to be an anonymous participant. Being able to participate in a discussion without having to face their peers and the teacher was a merit that pushed them beyond their safe zone. Although their names were known to everyone in the class, they explained that being in a different location gave them the courage to exchange their thoughts despite deficiencies in their language.

Such developments brought about a key change in students' perspective on classroom communication and contributed to the transformation of the collaborative learning process. Collaborative learning became situated in the everyday, and was maintained despite limitations of classroom time and space. Greater choice and control also allowed for improved quality of communication.

\section{Conclusion}

A supported language course was designed for the English department in Dammam University. Several tools, including the Internet, tablet devices, and course management, were explored with the goal of accommodating students' needs in the Saudi context.

Students in this study used the iPad device to learn English in a mobile assisted language learning environment. The conclusion drawn was that collaborative learning took place here in three different forms: working together, learning from peers, and exchange of feedback.

Results revealed a change in students' learning behavior as they became active learners and started to look for alternatives, provided via the tablet device, to perform group work activities and get involved in group related discussions to complete a given language task. In addition, such an environment suggested an enhanced social network between students and the facilitation of the appropriate psychological conditions for students to be more courageous and willing to give and receive feedback. The increased contact among students created a less threatening atmosphere in which students were encouraged to access the different communication channels available via the tablet devices to either post their answers to a given task or reflect on what 
others had posted. In addition, feedback became a part of the interactive process of learning, which fostered conversation among students and enabled every student to share in their negotiation of their participations.

Three main affordances provided by the iPad device were highlighted as those which brought about positive change in the collaborative learning process. They comprise: the quantity, the quality, and the control of communication.

Such findings indicate that the introduction of the iPad into a language learning course has significant potential to foster greater interaction between peers, promote student engagement and motivation to learn the target language, and therefore enable fuller student collaboration.

\section{$7 \quad$ References}

[1] Becta, (2004, 22/1/2017). What the Research Says About Portable ICT Devices in Teaching and Learning. Available: http://mirandanet.ac.uk/wp-content/uploads/2016/04/ wtrs 03 portable devices.pdf

[2] V., Braun, and V. Clarke, "Using Thematic Analysis in Psychology," Qualitative Research in Psychology, vol. 3, pp. 77-101, 2006. https://doi.org/10.1191/1478088706qp063oa

[3] Y. Chen et al., "A mobile scaffolding-aid-based bird-watching learning system," in IEEE International Workshop, 2002, pp. 15-22.

[4] C. Crook, "Motivation and the ecology of collaborative learning," in Rethinking collaborative learning, Joiner R. et al., Ed., ed London: Free Association Press, 2000, pp. 161-178.

[5] M. Denk et al., "Mobile learning-challenges and potentials," International Journal of Mobile Learning and Organisation, vol. 1, pp. 122-139, 2007. https://doi.org/10.1504/ IJMLO.2007.012674

[6] M. Dornyei, and T. Murphy, Group Dynamics in the Classroom. Cambridge: Cambridge University Press, 2003.

[7] H. Fleming, and D. Hiple, "Distance Education to Distributed Learning: Multiple Formats and Technologies in Language Instruction," CALICO, vol. 22, pp. 63-82, 2004.

[8] A. Jones et al., "Using mobile devices for learning in informal settings: Is it motivating?" in IADIS Mobile Learning Dublin, 2006, pp. 251-255.

[9] H. Kim et al., "An introduction to current trends and benefits of mobile wireless technology use in higher education," AACE Journal, vol. 14, pp. 77-100, 2006.

[10] A. Kukulska-Hulme, "Will Mobile Learning Change Language Learning," Recall, vol. 21, pp. 157-165, 2009. https://doi.org/10.1017/S0958344009000202

[11] A. Kukulska-Hulme, "Time and Place in Mobile Language Learning," in Left to my own devices: Learner autonomy and mobile-assisted language learning, J. Vera, Ed., ed Bingley: Emerald Group, 2012, pp. 6-20.

[12] A. Kukulska-Hulme et al., Mobile pedagogy for English language teaching: A guide for teachers. London: British Council, 2015.

[13] L. Naismith et al., "Literature review in mobile technologies and learning," ed. UK, 2004.

[14] M. Reed et al., (2010, 22/1/2017). What is social learning. 15(5). Available: http://www.ecologyandsociety.org/vol15/iss4/resp1

[15] H. Ryu, and D. Parsons, Innovative Mobile Learning: Techniques and Technologies. New York: Information Science, 2009. https://doi.org/10.4018/978-1-60566-062-2

[16] R. Schmuck, and A. Schmuck, Group Processes in the Classroom. Boston: MA: McGraw Hill, 2001. 
Paper-An Investigation into the Role of Tablet Devices in Facilitating Collaborative Learning in EFL..

[17] S. Thomas, "Pervasive, persuasive eLearning: modelling the pervasive learning space," presented at the Third IEEE International Conference, 2005. https://doi.org/10.1109/ percomw.2005.63

[18] G. Vavoula, and Sharples, M., "Challenges in evaluating mobile learning," in MLearn, UK, 2008, pp. 1-8.

[19] L. Vygotsky, Mind in society. Cambridge: Harvard University Press, 1978.

\section{Author}

Haifa Albadry is a Ph.D. candidate in Educational and Applied Linguistics at Newcastle University, UK. Her doctoral work explores the potential effects of mobile devices in particular, the tablet devices on language learner autonomy collaboration, and motivation.

Article submitted 06 February 2017. Published as resubmitted by the author 24 March 2017. 